Research Article

\title{
Strategic Provision of Trade Credit in a Dual-Channel Supply Chain
}

\author{
Qin Wan $\mathbb{D}^{1},{ }^{1}$ Yu Huang, ${ }^{1}$ Cuiting Yu, ${ }^{1}$ and Meili Lu $\mathbb{D}^{2}$ \\ ${ }^{1}$ School of Economics and Management, Southwest Petroleum University, Chengdu, Sichuan 610500, China \\ ${ }^{2}$ Business Administration College, Shanxi University of Finance and Economics, Taiyuan 030006, China \\ Correspondence should be addressed to Meili Lu; lumeilii@126.com
}

Received 16 March 2021; Revised 16 November 2021; Accepted 17 November 2021; Published 17 December 2021

Academic Editor: Vivek Roy

Copyright (c) 2021 Qin Wan et al. This is an open access article distributed under the Creative Commons Attribution License, which permits unrestricted use, distribution, and reproduction in any medium, provided the original work is properly cited.

This study focuses on a dual-channel supply chain that consists of a capital-constrained brick-and-mortar retailer and a manufacturer, where a manufacturer can simultaneously sell products through a traditional retail channel and a direct online channel. Supplementary pricing strategy and competitive pricing strategy are simulated in our model, and we find that the former one is the better choice for the manufacturer when the retailer suffers capital constraints. In our analysis, the capital constraint on retailer could mitigate the price competition between two channels, and it may be beneficial to the manufacturer under certain conditions. Our findings show that the manufacturer should strategically provide trade credit to retailers rather than unconditionally provide it. We present two trade-credit strategies (trade credit with positive interest rate and trade credit with zero interest rate) and suggest that the manufacturer should choose an appropriate trade-credit strategy according to the initial capital of the retailer. To guide the manufacturer when and how to provide trade credit, we conduct several numerical simulations based on our results and further plot out a graph to direct the manufacturer to an appropriate strategy of trade credit.

\section{Introduction}

More and more manufacturers have joined into the dualchannel supply chain, which combines a direct online channel with a physical retail channel. Manufacturers such as P\&G, IBM, Nike, Sony, Huawei, Granz, and Gree have succeeded in selling products through establishing official shopping websites or founding flagship stores on some B2C platforms. Some retail giants such as Walmart and Gome have owned mature physical stores and often play a dominant role in a supply chain through intervening manufacturers' pricing strategies such as wholesale price or retail price. Some manufacturers may break up the cooperation with retail giants if they cannot endure the inferior position in the supply chain. Like the Chinese manufacturer, Gree Inc. had withdrawn all kinds of products from the physical stores of the retail giant Gome in 2004 and turned to cooperate with other small or medium retailers. However, small or medium retailers usually have capital-constrained problems and need manufacturer's financing support although they do not intervene in manufacturers' pricing strategies. Commonly, small and medium firms are difficult to obtain financial supports from financial intermediaries such as banks (Petersen and Rajan [1]). So, it is a very practical issue to help manufacturers explore how to strategically offer financial services to small or medium retailers.

Trade credit is a common economic phenomenon in the supply chain, and it is used by the supplier for encouraging a capital-constrained retailer to order more quantities. Delay in payment is the most prominent feature of trade credit, and it is classified into several categories by Piasecki [2], Molamohamadi et al. [3, 4], which includes (1) pay as sold; (2) pay as sold during a predefined period; (3) pay as sold after a predefined period; and (4) pay for the prior order at the time of establishing the new replenishment. Trade credit is usually regarded as the third type of delay in payment, which means that the retailer is permitted to delay payment until the end of the credit period and be charged interest by a supplier. With trade credit, a capital-constrained retailer could get full order quantity by paying an initial capital and 
paying off the unpaid amount with an interest rate after the sale season ends (Cai et al. [5]). Trade credit is widely studied in a single-channel supply chain, while few studies address trade credit in a dual-channel supply chain. In a singlechannel supply chain, a traditional view is that retailer's capital constraint hurts the manufacturer's profit because it prevents the retailer from affording full order quantity. However, the capital constraint on retailer could mitigate the price competition between channels in a dual-channel supply chain; thus, the manufacturer may benefit from it. Different from the traditional view, this study puts forward that retailer's capital constraint is a double-edged sword for the manufacturer, and it is important for the manufacturer to make a strategic provision of trade credit. In this study, we try to investigate when and how a manufacturer should adopt trade credit in a dual-channel supply chain.

In a dual-channel supply chain, the manufacturer should afford the cost of selling products through a direct online channel, including building cost of the channel, advertising cost, and operating cost. Therefore, there is a need to incorporate a direct channel sales cost into the study. But most of the existing studies assume the sales cost in a direct channel is zero for simplicity of calculation, and only a few pieces of literature consider it. Suchlike, Chen et al. [6], Xu et al. [7], Xiong et al. [8], Yan et al. [9], Jing et al. [10], Gao et al. [11], Hu et al. [12], and Matsui [13], respectively, discuss different kinds of strategies for dual-channel supply chain considering direct channel sales cost. Extending to these studies, we probe into the manufacturer's pricing and trade credit strategy considering a direct channel sales cost.

Furthermore, an important difference between the two channels is that consumers can really inspect and immediately possess products through the traditional retail channel, but consumers not only face some uncertainty due to the lack of detailed physical inspection but also need the patience to wait for the delivery lead time through the direct online channel. Balasubramanian [14], Liang and Huang [15], and Kacen et al. [16] present that consumers' acceptance level of the direct online channel is generally lower than that of the traditional retail channel. Then, many studies are conducted based on their research studies, that is, Chiang et al. [17], Zhang et al. [18], Pei and Yan [19], Hua et al. [20], Rofin and Mahanty [21], and Guo et al. [22] study dual-channel supply chain considering consumers' acceptance level of the direct channel. Therefore, besides the direct channel sales cost, consumers' acceptance level of the direct channel also has a non-negligible effect on the manufacturer's profit.

Our model focuses on a Stackelberg game between manufacturer and retailer, by incorporating consumers' acceptance level of the direct channel and the sales costs in both channels, and several key questions should be taken into consideration by the manufacturer:

(1) Is a capital constraint always bad for the retailer? Is a capital-constrained retailer willing to be financed by trade credit?

(2) If the capital constraint on the retailer is harmful to the manufacturer's benefit, is providing trade credit to the retailer a better choice?
(3) If the manufacturer decides to provide trade credit to the retailer, how should the manufacturer strategically make the pricing and trade credit strategy?

In a dual-channel supply chain, the first key finding of this study is demonstrating that the manufacturer may benefit from the retailer's capital constraint, especially when consumers' acceptance level of the direct channel is relatively high and the unit sales cost in the direct channel is relatively low. Second, we present the equilibrium pricing and tradecredit strategy in different situations. Lastly, we plot out a directed graph that could guide the manufacturer to choose an appropriate strategy of trade credit. Our findings also provide some managerial insights for supply chain members. A capital-constrained retailer would not accept trade-credit service even if the manufacturer provides it especially when the cost of trade credit is high enough. Additionally, we suggest the manufacturer should strategically offer trade credit with a positive interest rate or with zero interest rate according to certain conditions.

We organized the remainder of this study as follows. In Section 2, we review the relevant literature. In Section 3, we introduce the benchmark model without trade credit. In Section 4, we expand the benchmark model with a tradecredit setting. In Section 5, we comprehensively conduct several numerical simulations. In Section 6, we finally make conclusions of our results.

\section{Relevant Literature}

There have been a lot of research studies on trade credit. Haley and Higgins [23] first discuss trade-credit policy by jointly considering the optimal order quantity and payment time. Goyal [24] develops the economic order quantity (EOQ) model under trade credit and presents the optimal replenishment policy. Chang et al. [25] present a review of inventory literature about trade credit by dividing related articles into five categories. Extending to Chang et al.'s [25] study, Molamohamadi et al. [4] exhaustively review the related literature by classifying trade-credit contracts into six categories. According to different model characteristics, Soni et al. [26] classify inventory studies into three categories. Tang et al. [27] and Zhang et al. [28] focus on the optimal terms in trade-credit contact, and $\mathrm{Xu}$ et al. [29] accommodate consumers' behavior into trade-credit provision. Peura et al. [30] and Ren et al. [31] explore pricing decisions of supply chain members under trade credit. Since our emphasis is trade-credit provision to a capital-constrained retailer in a dual-channel supply chain, this study is primarily relevant to three literature streams, including trade credit in a capital-constrained supply chain, the sales cost in the direct channel, and consumers' acceptance of direct online channel.

The first stream of literature addresses trade credit in a capital-constrained supply chain. Trade credit is widely studied in a single-channel supply chain. Xu and Birge [32] discuss the optimal decisions that depend on a firm's financial constraint under trade credit. Daripa and Nilsen [33] investigate the theory of interfirm credit that consists of 
prepayment and delayed payment (trade credit) and find that most of the credit is provided at a zero interest rate. Chen and Wang [34] prove supply chain members can share the risk from the market in a trade-credit contract and point that not only the order quantity but also the trade-credit contract terms are sufficiently affected by the retailer's initial budget. In line with Chen and Wang [34], Yang and Birge [35] also present that supply chain members could share the demand risk, and supply chain's performance could be improved by trade credit. Yan and He [36] examine the optimal trade-credit terms based on multiple decision attributes such as bankruptcy cost and service level. Zhan et al. [37] explore the trade-credit strategy involving a manufacturer and two competing retailers. Lin and Xiao [38] study a credit guarantee scheme to help a capital-constrained manufacturer in a supply chain. Some pieces of literature make comparisons between trade-credit financing (TCF) and bank-credit financing (BCF) for a capital-constrained supply chain. Such as Kouvelis and Zhao [39] consider that both supplier and retailer are capital constrained, investigate Stackelberg games between supply chain, and find that retailer is more likely to choose TCF rather than BCF if the supplier could provide an optimal trade-credit contract. Only considering that the retailer suffers the capital-constrained problem, Jing et al. [40] find that the equilibrium region of TCF will shrink if the initial budget of the retailer is improved to a higher level. Gupta [41] compares TCF with BCF considering that both financing tools are not competitively priced. Different from Gupta's [41] study, Chen [42] assumes there exists competition between TCF and BCF and demonstrates both supply chain members are worse off under BCF than TCF, but TCF is more difficult to implement in practice than BCF since the retailer may cheat on manufacturer about the true initial budget. Cai et al. [5] present that TCF and BCF can be complementary or substitutable if the retailer's internal capital satisfies corresponding conditions. Most kinds of literature in this stream reveal that the optimal decision of supply chain members and the optimal trade-credit contract terms are significantly influenced by the retailer's initial capital budget level. However, there is only a little literature that incorporates operational considerations within a capital-constrained dual-channel supply chain setting. Yan et al. [43] investigate the pricing strategy in a dual-channel supply chain, which includes a capital-constrained supplier and an e-retailer. They demonstrate that e-retailer financing not only increases market share but also benefits both supply chain members. Extending to Yan et al.'s [43] study, Yan et al. [44] accommodate a capital-constrained supplier, a physical retailer, and an e-commerce platform (ECP) into a dualchannel supply chain. By analyzing the free-riding effect of sales efforts from the retailer and ECP, they find that free riding can benefit all channel players if the supplier is financed by ECP. Li et al. [45] discuss three financing strategies in a dual-channel supply chain, which consists of a capital-constrained manufacturer and a supplier, and they find that the bank loan is always dominated by trade credit or hybrid financing. Zhen et al. [46] examine the financial strategies of a capital-constrained manufacturer who could borrow money from a bank or other channel members including a third-party platform and a retailer. They also present that the performance of credit financing provided by other channel members is better than that of bank financing in most cases. Different from these studies focusing on a capital-constrained manufacturer in a dual-channel supply chain, we concentrate on a capital-constrained physical retailer. This study explores how does the retailer's initial capital level influences the decisions of channel members and the terms of trade-credit contract under a capitalconstrained dual-channel supply chain.

Next, we review the literature related to the sales cost in the direct channel. Most of the existing studies assume the sales cost in the direct channel is zero for simplicity of calculation in a dual-channel supply chain, and only a few works of literature consider it. Chen et al. [6] suggest that a manufacturer adopts a share profit channel strategy when the sales cost in the direct channel is relatively high and the inconvenience cost of the retailer is relatively low. Xu et al. [7] investigate the optimal price and delivery lead time decisions in a dual-channel supply chain and find that the manufacturer should choose appropriate channel structure according to the value of direct channel cost and consumers' acceptance of the online channel. Xiong et al. [8] point out that the manufacturer would like to adopt a direct channel only when its sales cost is low enough. Yan et al. [9] present that expansion of e-channel could bring Pareto gains to dual-channel supply chain members if direct sales cost and product durability satisfy certain conditions. Jing et al. [10] study the optimal pricing policies for complementary products in a dual-channel supply chain considering direct channel sales cost. Gao et al. [11] investigate not only the operational cost in two channels but also the cost information asymmetry between supplier and retailer. $\mathrm{Hu}$ et al. [12] find that direct selling price, retail price, and the level of sales efforts would be reduced if sales cost increases. Matsui [13] finds that optimizing the bargaining timing of the wholesale price could generate higher profit for a manufacturer when the direct sales cost is relatively high. Extending to the above literature, this study aims to study the influence of sales cost in both channels on channel members' decision-making in a dual-channel supply chain, and it demonstrates that sales cost should not be ignored in trade-credit strategy.

The last stream of studies is related to consumers' acceptance of the direct online channel. Based on building normative models or conducting empirical research studies, Balasubramanian [14] and Liang and Huang [15] prove that consumers' acceptance level of the traditional retail channel is generally higher than that of the direct online channel. Kacen et al. [16] find that both the categories and attributes of products affect consumers' acceptance level of the online channel. Considering consumers' acceptance level of the direct online channel, Chiang et al. [17] explore the pricing strategy under a dual-channel supply chain. Extending to Chiang et al.'s [17] study, Yan et al. [47], Xu et al. [7], and Zhang et al. [18], respectively, investigate the influence of consumers' acceptance on advertisement strategy, service strategy, and channel selection strategy under a dual- 
channel supply chain. Consumers' acceptance level is also called "channel substitutability" or "channel preference" by some scholars. For instance, Pei and Yan [19] present that higher channel substitutability is more beneficial to channel members if the manufacturer invests in national advertising in a dual-channel supply chain. Hua et al. [20] find that the customers' preference level of a direct channel has a positive effect on the direct sales price. Rofin and Mahanty [21] present that the direct channel preference level is positively related to direct channel demand, and a high direct channel preference level will lead to a high online sale price and a low offline sale price. Guo et al. [22] find that consumers' acceptance level of online channels has an important impact on manufacturers' preference for a centralized or decentralized supply chain. Existing research studies show that the consumers' acceptance of direct online channel significantly affects kinds of strategies in a dual-channel supply chain, so this study also accommodates this factor into our model.

Above all, in this study, we simultaneously consider the sales cost in both channels and consumers' acceptance level of the direct channel and try to explore a dual-channel supply chain fundamental for the efficiency of the tradecredit strategy.

\section{Dual-Channel Supply Chain without Trade- Credit Service}

Considering that a dual-channel supply chain consists of a manufacturer and a capital-constrained physical retailer, the manufacturer produces a kind of product at a unit production cost $c$ and sells the product through a direct online channel (hereafter called direct channel) and a traditional retail channel (hereafter called retail channel). In the direct channel, the manufacturer directly sells the product to consumers at the price $p_{d o}$ and endures a unit sales cost $z_{d}$; in the retail channel, the manufacturer supplies retailer at a unit wholesale price $w$, and the retailer sells the product at the price $p_{r o}$ in a physical store and occurs a unit sales cost $z_{r}$. A manufacturer practically adopts a uniform wholesale price when it deals with different retailers. Since the unit wholesale price of the product is the result of competition among multiple manufacturers in the market, and it infrequently changes relative to the retail price, in line with $\mathrm{Hu}$ et al. [12], Zhang et al. [28], Xu et al. [29], Gupta [41], and Cai et al. [5], we assume the wholesale price $w$ is an exogenous parameter. All notations are summarized in Table 1. Three scenarios, denoted by the subscript $i=o, c, t c$, are identified. They include (1) the retailer has no capital constraint $(i=o)$; (2) the retailer suffers capital constraint but without trade-credit provision $(i=c)$; and (3) the retailer suffers capital constraint and is financed by trade credit from the manufacturer $(i=t c)$.

3.1. Consumer Utility and Purchase Decision. Similar to Chiang et al. [17], Yan et al. [47], Xu et al. [7], Zhang et al. [18], and Guo et al. [22], we, respectively, denote a consumer's valuation of the product by $v$ in the retail channel and $\theta v$ in the direct channel, where the parameter $\theta$ is called
TABLE 1: Notation summary.

\begin{tabular}{lc}
\hline$c$ & Unit production cost \\
$z_{d}$ & Unit sales cost in the direct channel \\
$z_{r}$ & Unit sales cost in the retail channel \\
$w$ & Unit wholesale price \\
$v$ & Consumer's valuation of the product \\
$t_{r}$ & Unit transportation cost, $t_{r} \geq 0$ \\
$t_{d}$ & Logistic delivery cost, $t_{d} \geq 0$ \\
$\theta$ & Consumers' acceptance level of direct channel, $0<\theta \leq 1$ \\
$x$ & Consumer's location, $x \sim U[0,1]$ \\
$B$ & Retailer's initial capital budget \\
$q_{i}$ & Retailer's order quantity under scenario $i, i=o, c, t c$ \\
$r$ & The interest rate for delay payment in trade credit, $r \geq 0$ \\
$p_{d i}$ & The sales price in the direct channel under scenario $i$, \\
$p_{r i}$ & $i=o, c, t c$ \\
$L$ & The retail price under scenario $i, i=o, c, t c$ \\
\hline
\end{tabular}

the consumers' acceptance level of the direct channel. According to the research results of Liang and Huang [15] and Kacen et al. [16], most consumers prefer buying goods from bricks and mortar to web-based channels since there are more uncertainty and risks in buying online. So, we develop a model in this study with $0<\theta \leq 1$. It is assumed each consumer's location $x(x \sim U[0,1])$ is uniformly distributed along a unit line and a retailer is at location 0 . If a consumer located at $x(x \sim U[0,1])$ travels to the retailer's store, the consumer will incur a transportation cost $t_{r} x$, where $t_{r}\left(t_{r} \geq 0\right)$ is the unit transportation cost. Then, the utility function of one consumer who buys the product through traveling to retailer's store is $(i=o, c, t c)$

$$
U_{r i}=v-p_{r i}-t_{r} x
$$

As for the consumer who to buy from the direct channel, besides the product's sales price, he needs to afford logistic delivery cost rather than transportation cost. From any manufacturers' official shopping websites (such as Huawei and Gree Inc.), it can be easy to find that the difference in logistic delivery cost among different regions in a country is not significant, and the delivery cost is even free if the consumption amount attains to some threshold at most cases. Therefore, we assume that a consumer needs to pay a constant logistic delivery cost $t_{d}\left(t_{d} \geq 0\right)$ if he directly buys a product through the manufacturer's website, and his utility function is $(i=o, c, t c)$

$$
U_{d i}=\theta v-p_{d i}-t_{d}
$$

To assure that the manufacturer has an incentive to build a direct channel, it is appropriate to assume the consumer's valuation of the product in a retail channel that satisfies $v<w+z_{r}+2 t_{r}$. The condition $v<w+z_{r}+2 t_{r}$ indicates the retailer cannot completely cover the whole market, so the manufacturer could efficiently improve market demand through building a direct channel. We further assume $v>w+z_{r}$ to ensure the demand in the retail channel is nonnegative. In addition, we normalize consumers' amount to 1 and suppose any individual consumer can buy (at most) one product from one channel. A consumer will buy from the 


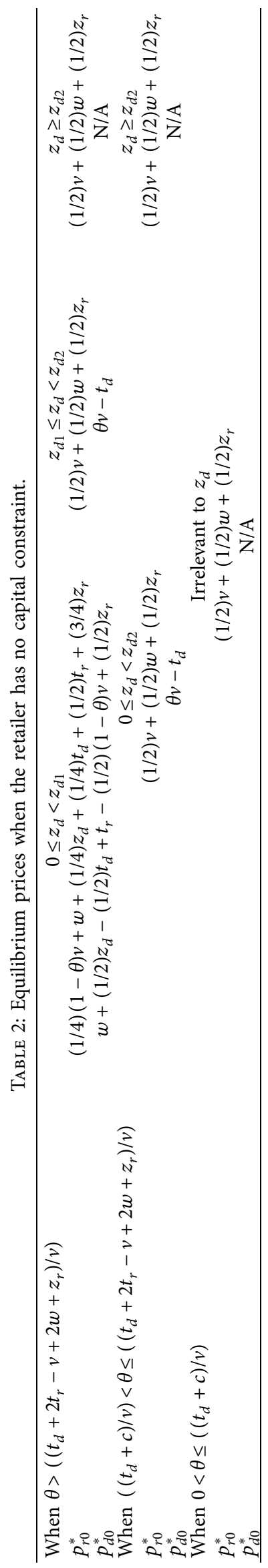


retail channel (or direct channel) if his utility is non-negative and always prefer the higher one if both channels' utility is positive. Then, we can find that the indifference point of the consumer's location is $\left(\left(v-p_{r}-\theta v+p_{d}+t_{d}\right) / t_{r}\right)$, consumers located in $0 \leq x \leq\left(\left(v-p_{r}-\theta v+p_{d}+t_{d}\right) / t_{r}\right)$ will buy from the retail channel, and consumers located in $\left(\left(v-p_{r}-\theta v+p_{d}+t_{d}\right) / t_{r}\right)<x \leq 1$ will buy from the direct channel.

\subsection{Pricing Strategy of the Manufacturer When the Retailer} Has No Capital Constraint $(i=o$ ). When a retailer has no capital constraint, we, respectively, denote the online direct selling price and retail price of the product by $p_{d o}$ and $p_{r o}$. According to the consumers' purchase decisions in Section 3.1 , the order quantity of the retailer is denoted by $q_{o}$, which equals to $\left(\left(v-p_{r o}-\theta v+p_{d o}+t_{d}\right) / t_{r}\right)$; then, the retailer's profit function $\pi_{r o}\left(p_{r o}\right)$ is

$$
\begin{aligned}
\pi_{r o}\left(p_{r o}\right) & =\left(p_{r o}-w-z_{r}\right) q_{o} \\
& =\left(p_{r o}-w-z_{r}\right) \frac{v-p_{r o}-\theta v+p_{d o}+t_{d}}{t_{r}} .
\end{aligned}
$$

The market share obtained by the manufacturer through building the direct channel is $\left(1-\left(\left(v-p_{r o}-\theta v+\right.\right.\right.$ $\left.\left.\left.p_{d o}+t_{d}\right) / t_{r}\right)\right)$, and its profit function $\pi_{m o}\left(p_{d o}\right)$ is

$$
\begin{aligned}
\pi_{m o}\left(p_{d o}\right)= & (w-c) q_{o}+\left(p_{d o}-c-z_{d}\right)\left(1-q_{o}\right) \\
= & (w-c) \frac{v-p_{r o}-\theta v+p_{d o}+t_{d}}{t_{r}} \\
& +\left(p_{d o}-c-z_{d}\right)\left(1-\frac{v-p_{r o}-\theta v+p_{d o}+t_{d}}{t_{r}}\right) .
\end{aligned}
$$

The first part of equation (4) is the wholesale revenue in the retail channel, and the latter part is the profit generated by the direct channel. It is supposed that both manufacturer and the retailer are independent of each other and, respectively, profit-seeking. We utilize a manufacturer-leader Stackelberg game to explore the optimal prices of supply chain members. The manufacturer first decides the direct sales price $p_{d o}$; then, the retailer makes the optimal response and decides the retail price $p_{r o}$ in the physical store. To ensure that both channels' market demand and the marginal profit are non-negative, we can reasonably infer the constraint conditions $w+z_{r} \leq p_{r o} \leq v$ and $c+z_{d} \leq p_{d o} \leq \theta v-t_{d}$ about the direct sales price $p_{d o}$ and the retail price $p_{r o}$. Thus, the retailer and the manufacturers' optimization problems are, respectively, as follows:

$$
\begin{array}{ll}
\operatorname{Max}_{p_{r o}} \pi_{r o}\left(p_{r o}\right), & \text { st. } w+z_{r} \leq p_{r o} \leq v, \\
\operatorname{Max}_{p_{d o}} \pi_{m o}\left(p_{d o}\right), & \text { st. } c+z_{d} \leq p_{d o} \leq \theta v-t_{d} .
\end{array}
$$

Base on the backward induction method, we present the equilibrium prices for both channels in Table 2, where $z_{d 1}=$ $\theta v-t_{d}-2 t_{r}+v-2 w-z_{r}$ and $\mathrm{z}_{d 2}=\theta v-c-t_{d}$. It can be found that the equilibrium prices of both channels are simultaneously affected by the consumers' acceptance level of the direct channel $\theta$ and the unit sales cost in the direct channel $z_{d}$.

Table 2 shows that if the value of consumers' acceptance level of direct channel $\theta$ is no more than the threshold $\left(\left(t_{d}+c\right) / v\right)$, the manufacturer does not need to build a direct channel. If the value of $\theta$ is higher than $\left(\left(t_{d}+c\right) / v\right)$, the direct channel is also unattractive to the manufacturer as long as the unit sales cost in the direct channel $z_{d}$ is relatively high, i.e., exceeds the threshold $z_{d 2}$. Otherwise, both players in the dual-channel supply chain should decide the optimal prices based on the value of $\theta$ and $z_{d}$. In addition, the equilibrium prices $p_{d 0}^{*}$ and $p_{r 0}^{*}$ are monotonically increasing and decreasing with respect to $\theta$, respectively, and it shows that a higher consumers' acceptance level of the direct channel will bring a higher direct sales price and a lower retail price. These findings are in line with the results presented by Hua et al. [20] and Rofin and Mahanty [21].

There are two pricing strategies for the manufacturer in the direct channel. The one is the supplementary pricing strategy, which sets a relatively high direct sales price to just absorb the market demand that cannot be satisfied by the retailer. Understandably, there is no competition between $p_{d 0}^{*}$ and $p_{r 0}^{*}$ in supplementary pricing strategy. Another one is the competitive pricing strategy. Besides absorbing the market demand, which cannot be satisfied by the retailer, the manufacturer could poach the retailer's market share by setting a relatively low direct sales price. We put the optimal pricing strategy for the manufacturer in Proposition 1.

Proposition 1. If the unit online direct selling cost $z_{d}$ does not exceed the threshold $z_{d 2}$, the manufacturer should build a direct channel and choose an appropriate pricing strategy according to the value of the consumers' acceptance level of the direct channel $\theta$ and the unit sales cost in the direct channel $z_{d}$ :

(1) When $\theta>\left(\left(t_{d}+2 t_{r}-v+2 w+z_{r}\right) / v\right)$, the manufacturer should adopt a competitive pricing strategy with setting $p_{d 0}^{*}=w+(1 / 2) z_{d}-(1 / 2) t_{d}+t_{r}$ $-(1 / 2)(1-\theta) v+(1 / 2) z_{r}$ if $0 \leq z<z_{d 1}$ and a supplementary price strategy with setting $p_{d 0}^{*}=\theta v-t_{d}$ if $z_{d 1} \leq z<z_{d 2}$.

(2) When $\left(\left(t_{d}+c\right) / v\right)<\theta \leq\left(\left(t_{d}+2 t_{r}-v+2 w+z_{r}\right) / v\right)$, the manufacturer should adopt the supplementary pricing strategy with setting the direct sales price $p_{d 0}^{*}=\theta v-t_{d}$.

(3) When $0<\theta \leq\left(\left(t_{d}+c\right) / v\right)$, the manufacturer does not need to build a direct channel.

Proposition 1 shows that the manufacturer should adopt the competitive pricing strategy in the direct channel only when consumers' acceptance level of the direct channel is relatively high and the unit sales cost in the direct channel is relatively low. Otherwise, the supplementary pricing strategy should be the better choice.

\subsection{Pricing Strategy of the Manufacturer When Retailer Suffers} Capital Constraint $(i=c)$. According to the result presented by Proposition 1, the manufacturer does not need to build a 
direct channel when the unit sales cost in the direct channel $z_{d}$ exceeds the threshold $z_{d 2}$, so this study only pays attention to the situation that $z_{d}$ satisfies $0 \leq z_{d}<z_{d 2}$. In this section, we consider the retailer has an initial capital $B$, which is insufficient to afford the order quantity $q_{o}^{*}$, i.e., $B<w \cdot q_{o}^{*} \quad\left(\right.$ where $\left.\quad q_{o}^{*}=\left(\left(v-p_{r o}^{*}-\theta v+p_{d o}^{*}+t_{d}\right) / t_{r}\right)\right)$. According to Table 1 , the equilibrium prices $\left(p_{r o}^{*}, p_{d o}^{*}\right)$ of both channels depend on the value of parameters $\theta$ and $z_{d}$, and sequentially the optimal order quantity of retailer $q_{o}^{*}$ is also determined by the value of the two parameters. So, the retailer will face a capital-constrained problem under the following situations presented in Lemma 1.

Lemma 1. The retailer will face a capital-constrained problem:

(1) When $\theta \leq\left(\left(t_{d}+2 t_{r}-v+2 w+z_{r}\right) / v\right)$, the retailer's initial capital satisfies $B \leq(w / 2)\left(\left(v-w-z_{r}\right) / t_{r}\right)$;

(2) When $\theta>\left(\left(t_{d}+2 t_{r}-v+2 w+z_{r}\right) / v\right)$, the retailer's initial capital satisfies $B<(w / 4)\left(\left((1-\theta) v+z_{d}+t_{d}+\right.\right.$ $\left.\left.2 t_{r}-z_{r}\right) / t_{r}\right)$ if $0 \leq z<z_{d 1}$, and $B<(w / 2)((v-w$ $\left.\left.-z_{r}\right) / t_{r}\right)$ if $z_{d 1} \leq z_{d}<z_{d 2}$.

With a capital-constrained problem, the retailer can only make order quantity $(B / w)$ based on his initial capital; then, the equilibrium prices in both channels should be further explored. The product's direct sales price and retail price are, respectively, denoted by $p_{d c}$ and $p_{r c}$. The retailer's profit function $\pi_{r c}\left(p_{r c}\right)$ and the manufacturer's profit function $\pi_{m c}\left(p_{d c}\right)$ are as follows:

$$
\begin{aligned}
\pi_{r c}\left(p_{r c}\right) & =\left(p_{r c}-w-z_{r}\right) \frac{B}{w} \\
\pi_{m c}\left(p_{d c}\right) & =(w-c) \frac{B}{w}+\left(p_{d c}-c-z_{d}\right)\left(1-\frac{B}{w}\right) .
\end{aligned}
$$

The manufacturer should set $c+z_{d} \leq p_{d c} \leq \theta v-t_{d}$ to ensure that the market demand and the marginal profit of the product are non-negative in the direct channel. As for the retailer, besides positive marginal profit, it is very important to ensure the market demand is not less than the order quantity $(B / w)$ through setting the retail price satisfying $w+$ $z_{r} \leq p_{r c} \leq\left(\left(\left((1-\theta) v+p_{d c}+t_{d}\right) w-B t_{r}\right) / w\right)$ in the retail channel. So, the optimization problems for dual-channel supply chain players are as follows:

$$
\begin{aligned}
& \operatorname{Max}_{p_{r}} \pi_{r c}\left(p_{r c}\right), \quad \text { st. } w+z_{r} \leq p_{r c} \leq \frac{\left((1-\theta) v+p_{d c}+t_{d}\right) w-B t_{r}}{w}, \\
& \operatorname{Max}_{p_{d}} \pi_{m c}\left(p_{d c}\right), \quad \text { st. } c+z_{d} \leq p_{d c} \leq \theta v-t_{d} .
\end{aligned}
$$

According to the backward induction method, we try to explore the equilibrium solutions to the manufacturer-leader Stackelberg game. Since the retailer's profit function $\pi_{r c}\left(p_{r c}\right)$ is monotonically increasing with the retail price $p_{r c}$, then, the response function of retail price can be first obtained

$$
p_{r c}\left(p_{d c}\right)=\frac{\left((1-\theta) v+p_{d c}+t_{d}\right) w-B t_{r}}{w} .
$$

Because the profit function of the manufacturer is monotonically increasing with the direct sales price, we can obtain

$$
p_{d c}^{*}=\theta v-t_{d} .
$$

After substituting (9) into (8), it can be found that the optimal retail price is

$$
p_{r c}^{*}=\frac{v w-B t_{r}}{w} .
$$

In Proposition 2, we present the manufacturer's pricing strategy and the influence of the retailer's capital constraint on the manufacturer's profit.

Proposition 2. If a retailer has a capital constraint and owns initial capital B,

(1) Manufacturer should always adopt the supplementary pricing strategy, and the equilibrium prices in two channels are $p_{d c}^{*}=\theta v-t_{d}$ and $p_{r c}^{*}=\left(\left(v w-B t_{r}\right) / w\right)$, respectively.

(2) Compared to without capital constraint, the capitalconstrained retailer will increase the manufacturer's profit if $\theta>\left(\left(t_{d}+w\right) / v\right)$ and $0 \leq z_{d}<z_{d 3}$; otherwise, it will decrease the manufacturer's profit, where $z_{d 3}=\theta v-t_{d}-w$.

When the retailer has a capital-constrained problem, Proposition 2 first shows that supplementary pricing strategy is the better choice for manufacturer rather than competitive pricing strategy. There is no need to compete with the retailer on price because the maximum profit can be realized by setting the highest direct sales price $p_{d c}^{*}=\theta v-t_{d}$. Second, the equilibrium retail price $p_{r c}^{*}$ is negatively related to the retailer's initial capital $B$ and irrelevant to the consumers' acceptance level of the direct channel $\theta$, while the equilibrium direct sales price $p_{d c}^{*}$ is positively correlated with $\theta$.

Furthermore, unlike the traditional view that the retailer's capital constraint is only bad for the manufacturer's profit, Proposition 2 reveals that the retailer's capital constraint has a two-way impact on the manufacturer's profit. On the one hand, it could ease price competition between two channels; thus, it has a positive effect on improving the marginal profit of the manufacturer. On the other hand, it reduces the retailer's order quantity, which hurts the manufacturer's wholesale income. When consumers' acceptance level of the direct channel is relatively high and the unit sales cost in the direct channel is relatively low, the positive impact from the retailer's capital constraint is stronger than the negative impact, so a capital constraint on the retailer is good for manufacturer. In other cases, the retailer's capital constraint is harmful to manufacturer's profit, so the manufacturer has an incentive to provide financial service to the retailer. To clearly describe when is the retailer's capital constraint beneficial to the manufacturer, we further plot out the beneficial region for the manufacturer according to corresponding conditions presented in 


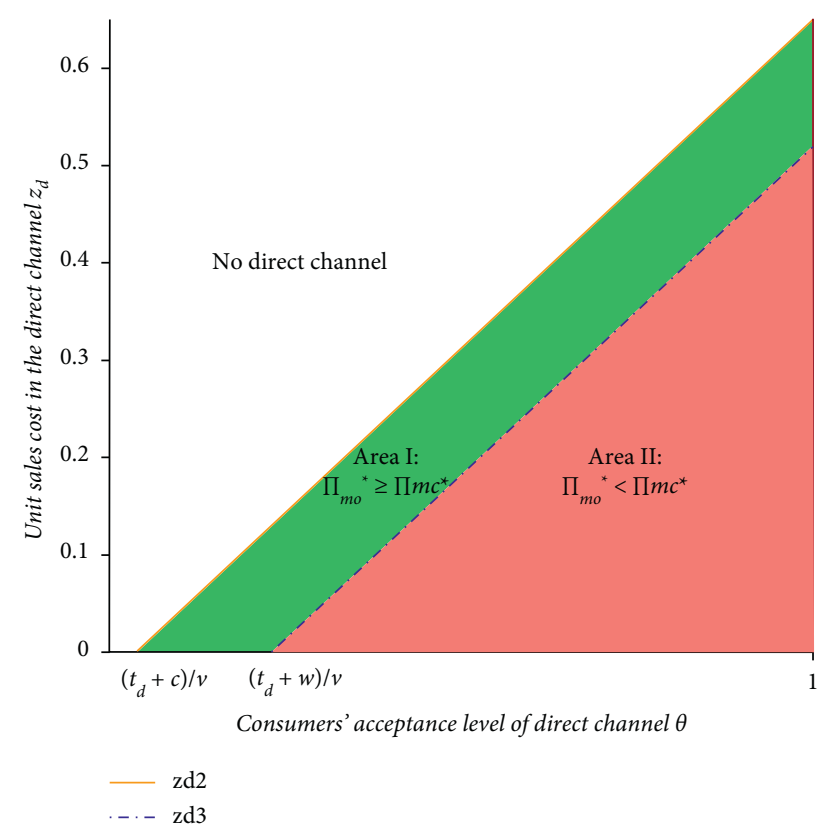

Figure 1: Manufacturer's profit under two scenarios $(i=o, c)$.

Proposition 2 (see Figure 1). Figure 1 shows that the capital constraint on the retailer is beneficial to the manufacturer in Area II, but the opposite occurs in Area I.

\section{A Dual-Channel Supply Chain with Trade- Credit Service $(i==t c)$}

We accommodate a specific financial service, which is trade credit in this section, and further discuss trade-credit strategy in a dual-channel supply chain. To avoid default risk, suppliers often encourage retailers to pay off unpaid amounts early by designing the appropriate trade-credit contract. In a single-channel supply chain, Kouvelis and Zhao [39] incorporate interest rate and discounted wholesale price into the trade-credit contract, and Cai et al. [5] discuss credit limit and interest rate in the trade-credit contract. Different from them, we jointly optimize the tradecredit strategy and pricing strategy by considering the interest rate and the online direct sales price $p_{d t c}$ into the contract under a dual-channel supply chain.

Based on Proposition 2, it can be found that the manufacturer has an incentive to provide trade credit only when its profit is pulled down by the retailer's capital constraint. The corresponding conditions are identified in Lemma 2.

Lemma 2. Manufacturer has an incentive to provide trade credit to a capital-constrained retailer in the following two cases:

Case (1): consumers' acceptance level of the direct channel is too low, i.e., $\left(\left(t_{d}+c\right) / v\right)<\theta \leq\left(\left(t_{d}+w\right) / v\right)$

Case (2): both consumers' acceptance level of the direct channel and the unit sales cost in direct channel are relatively high, i.e., $\theta>\left(\left(t_{d}+w\right) / v\right)$ and $z_{d 3} \leq z_{d}<z_{d 2}$

The above cases are included in Area I of Figure 1, and the retailer financed by trade credit could realize a larger order quantity than that afforded by initial capital B. Served by trade credit, the retailer firstly only needs to make a partial payment with his initial capital $B$ and then realizes full order quantity $((B+L) / w)$ right away, where $L(L \geq 0)$ is the delayed payment. The retailer must pay off the delay payment $L$ to the manufacturer at an interest rate $r(r \geq 0)$ after the sales season ends. In the manufacturer-leader Stackelberg game, the manufacturer firstly decides the terms in the tradecredit contract including online direct sales price $p_{d t c}$ and the interest rate $r$; then, the retailer makes the optimal response to the manufacturer's strategy and decides the delay payment $L$ and retail price $p_{r t c}$. The retailer's profit function $\pi_{r t c}\left(p_{r t c}, L\right)$ and the manufacturer's profit function $\pi_{m t c}\left(p_{d t c}, r\right)$ can be described as follows:

$$
\begin{aligned}
\pi_{r t c}\left(p_{r t c}, L\right) & =\left(p_{r t c}-w-z_{r}\right) \frac{B+L}{w}-L(1+r), \\
\pi_{m t c}\left(p_{d t c}, r\right) & =(w-c) \frac{B+L}{w}+\left(p_{d t c}-c-z_{d}\right)\left(1-\frac{B+L}{w}\right)+L r .
\end{aligned}
$$

As the same as Section 3.3, the manufacturer should set $c+z_{d} \leq p_{d t c} \leq \theta v-t_{d}$ to ensure that the market demand and the marginal profit are non-negative in the direct channel. Besides positive marginal profit, the retailer needs to ensure the market demand is not less than the order quantity $((B+$ $L) / w)$ through setting the retail price satisfying $w+z_{r} \leq p_{r t c} \leq\left(\left(\left((1-\theta) v+p_{d t c}+t_{d}\right) w-(B+L) t_{r}\right) / w\right)$ in the retail channel. So, the optimization problems for dualchannel supply chain players are as follows:

$$
\begin{aligned}
& \operatorname{Max}_{p_{r t c}, L} \pi_{r t c}\left(p_{r t c}, L\right), \quad \text { st. }\left\{\begin{array}{l}
w+z_{r} \leq p_{r t c} \leq \frac{\left((1-\theta) v+p_{d t c}+t_{d}\right) w-(B+L) t_{r}}{w} \\
L \geq 0,
\end{array}\right. \\
& \operatorname{Max}_{p_{d t c}, r} \pi_{m t c}\left(p_{d t c}, r\right), \quad \text { st. }\left\{\begin{array}{l}
c+z_{d} \leq p_{d t c} \leq \theta v-t_{d} \\
r \geq 0 .
\end{array}\right.
\end{aligned}
$$


The equilibrium solutions $\left(p_{r t c}^{*}, L^{*}\right)$ and $\left(p_{d t c}^{*}, r^{*}\right)$ are presented in Table 3 , where $B_{1}=\left(w\left(v-2 w-z_{r}\right) / 2 t_{r}\right)$, $B_{2}=\left(\left((1+\theta) v-z_{d}-z_{r}-t_{d}-3 w\right) w / 2 t_{r}\right)$.

After making a comparison between the value of $p_{r t c}^{*}$ in Table 3 and the value of $p_{r c}^{*}$ in Proposition 2, it can be found that $p_{r c}^{*} \geq p_{r t c}^{*}$ is always holding. It indicates that the retailer decreases the retail price of the product under trade credit, so trade credit could make the retail price more competitive in two channels. We further investigate whether the provision of trade credit is beneficial to the manufacturer and present the pricing strategy and trade-credit strategy in Proposition 3 .

Proposition 3. When manufacturer's profit is pulled down by retailer's capital constraint, the manufacturer should adopt the supplementary pricing strategy with $p_{d t c}^{*}=\theta v-t_{d}$ and strategically provide trade credit based on the value of the retailer's initial capital $B$ and the value of unit sales cost $z_{r}$ in the retail channel:

(1) When the value of unit sales cost in the retail channel $z_{r}$ is low enough to satisfy $z_{r}<(1+\theta) v-t_{d}-z_{d}-3 w$, (i) the manufacturer should provide trade credit to the retailer with a positive interest rate $r^{*}=(1 / 2)((((1+$ $\left.\left.\left.\theta) v-z_{d}-z_{r}-t_{d}\right) w-2 B t_{r}-3 w^{2}\right) / w^{2}\right)$ if $0 \leq B<B_{2}$; (ii) the manufacturer should provide trade credit to the retailer for free with $r^{*}=0$ if $B_{2} \leq B<B_{1}$; and (iii) the manufacturer does not need to adopt trade credit if $B_{1} \leq B<(w / 2)\left(\left(v-w-z_{r}\right) / t_{r}\right)$.

(2) When the value of unit sales cost in the retail channel $z_{r}$ satisfies $(1+\theta) v-t_{d}-z_{d}-3 w \leq z_{r}<v-2 w$, (i) the manufacturer should provide trade credit to the retailer for free with $r^{*}=0$ if $0 \leq B<B_{1}$, and (ii) the manufacturer does not need to adopt trade credit if $B_{1} \leq B<(w / 2)\left(\left(v-w-z_{r}\right) / t_{r}\right)$.

(3) When the value of unit sales cost in the retail channel $z_{r}$ is high enough to satisfy $v-2 w \leq z_{r}<v-w$, the manufacturer does not need to adopt trade credit.

Proposition 3 puts forward two trade-credit strategies: trade credit with positive interest rate and trade credit with zero interest rate. The results guide the manufacturer when and how to provide trade credit. Although trade credit could increase the manufacturer's wholesale revenue and bring income by interest rate, it will also lead the manufacturer to suffer profit loss since the competition between the two channels is intensified. On one hand, when the value of unit sales cost in retail channel is relatively low, the increment of manufacturer's profit is lower than the profit loss under the trade credit if the value of the retailer's initial capital is relatively high, i.e., $B_{1} \leq B<(w / 2)\left(\left(v-w-z_{r}\right) / t_{r}\right)$, so there is no need to provide trade credit at all; if the value of the retailer's initial capital is relatively low, i.e., $0 \leq B<B_{2}$, the opposite is true and the manufacturer should provide trade credit with a positive interest rate; note that when the value of retailer's initial capital is neither relatively high nor relatively low, i.e., $B_{2} \leq B<B_{1}$, the manufacturer would like to choose a zero interest rate to expand the wholesale income.
This result is consistent with the conclusion of Xu et al. [29] and Daripa and Nilsen [33] that much of the trade credit is supplied at zero interest. On the other hand, when the value of unit sales cost $z_{r}$ in the retail channel is extremely high (i.e., $v-2 w \leq z_{r}<v-w$ ), the retailer would not accept trade-credit service even if the manufacturer provides it since low retail price and high sales cost lead to low marginal profit under trade credit. So, there is no need to adopt trade credit under this situation.

To guide the manufacturer when and how to provide trade credit, we further plot out the feasible region for each trade-credit strategy based on the corresponding condition (see Figure 2). Our results implicate that making a tradecredit strategy according to the retailer's initial capital and the unit sales cost in the retail channel can effectively avoid the cheating problem, which is presented by Chen [42] that the retailer may cheat on the manufacturer about the true initial budget.

\section{Numerical Simulation}

Base on several numerical simulation examples, we comprehensively explore more managerial insights of pricing and trade-credit strategies in a dual-channel supply chain.

5.1. Without Trade Credit. We test the two-way impact from the retailer's capital constraint on the manufacturer's profit with the following base parameter set $w=0.28, c=0.15$, $v=0.9, t_{d}=0.1, t_{r}=0.12, z_{r}=0.1$. According to the second result presented in Proposition 2, we use the condition on consumers' acceptance level and unit sales cost in the direct channel to jointly form a closed region in a two-dimensional plane (see Figure 1).

Figure 1 shows that when consumers' acceptance level of the direct channel is relatively high and the unit sales cost in the direct channel is relatively low (i.e., in Area II), the manufacturer can benefit from the capital constraint on the retailer, while the opposite occurs in Area I. So the manufacturer does not need to adopt trade credit in Area II; however, the manufacturer should consider how to strategically provide trade credit to the retailer in Area I.

5.2. With Trade Credit. In this section, we, respectively, explore the impact of trade credit on the retailer's order quantity, retail price, and manufacturer's profit. Furthermore, we try to describe the feasible region for each tradecredit strategy based on corresponding conditions. According to Lemma 2, the next four numerical studies have been developed under conditions in which both consumers' acceptance level of the direct channel and unit sales cost in the direct channel are relatively high (i.e., $\theta>\left(\left(t_{d}+w\right) / v\right)$ and $\left.z_{d 3} \leq z<z_{d 2}\right)$. With the following base parameter set $w=0.28, c=0.15, v=0.9, t_{d}=0.1$, $t_{r}=0.12, z_{r}=0.1, \theta=0.65, z_{d}=0.24$, we first, respectively, plot the order quantity of retailer $q_{o}^{*}, q_{c}^{*}(B)$ and $q_{t c}^{*}(B)$ under three scenarios: (1) the retailer has no capital constraint; (2) the retailer suffers capital constraint but without 
TABle 3: Equilibrium outcomes with trade-credit service.

\begin{tabular}{lccc}
\hline & $0 \leq B<B_{2}$ & $B_{2} \leq B<B_{1}$ & $B_{1} \leq B<(w / 2)\left(\left(v-w-z_{r}\right) / t_{r}\right)$ \\
\hline$p_{r t c}^{*}$ & $(1 / 4)\left(\left(\left((3+\theta) v-z_{d}+z_{r}-t_{d}\right) w-2 B t_{r}+w^{2}\right) / w\right)$ & $(1 / 2) v+w+(1 / 2) z_{r}$ & $\left(\left(v w-B t_{r}\right) / w\right)$ \\
$L^{*}$ & $(1 / 4)\left(\left(\left((1-\theta) v+z_{d}-z_{r}+t_{d}\right) w-2 B t_{r}-w^{2}\right) / t_{r}\right)$ & $(1 / 2)\left(\left(v w-2 B t_{r}-2 w^{2}-w z_{r}\right) / t_{r}\right)$ & N/A (no trade credit) \\
$p_{d t c}^{*}$ & $\theta v-t_{d}$ & $\theta v-t_{d}$ & $\theta v-t_{d}$ \\
$r^{*}$ & $(1 / 2)\left(\left(\left((1+\theta) v-z_{d}-z_{r}-t_{d}\right) w-2 B t_{r}-3 w^{2}\right) / w^{2}\right)$ & 0 & N/A (no trade credit) \\
\hline
\end{tabular}

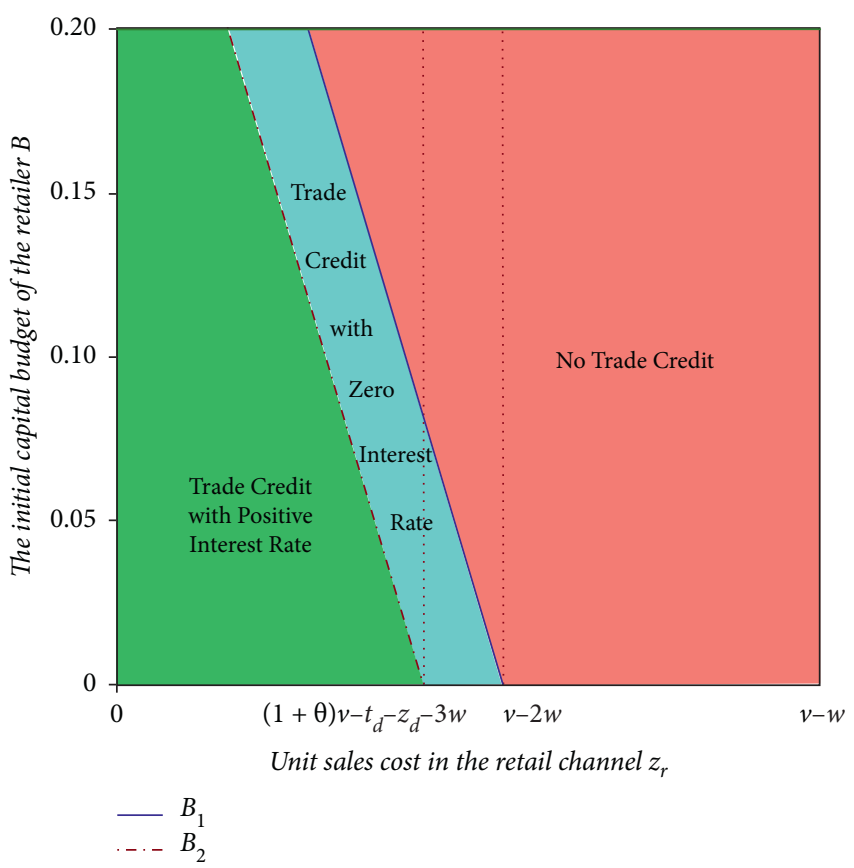

FIgURE 2: The feasible region of trade-credit strategy.

trade-credit provision; and (3) the retailer suffers capital constraint and is financed by trade credit from the manufacturer.

Figure 3 shows that under the above three scenarios, the retailer's order quantity always meets $q_{c}^{*}(B) \leq q_{t c}^{*}(B) \leq q_{o}^{*}$. It indicates that capital constraint compels the retailer to reduce his order quantity from the $q_{o}^{*}$ to $q_{c}^{*}(B)$, while the trade credit could improve his order quantity from $q_{c}^{*}(B)$ to $q_{t c}^{*}(B)$. It is worth noting that the retailer will not improve its order quantity $q_{t c}^{*}(B)$ up to $q_{o}^{*}$ even if the manufacturer serves him with trade credit for free. Since the trade credit with zero interest rate puts down the retail price although it improves the order quantity, therefore, blindly pursuing the order level without capital constraint may not bring the maximum profit.

Then, we describe the retail price $p_{r o}^{*}, p_{r c}^{*}(B)$, and $p_{r t c}^{*}(B)$ under the above three scenarios in Figure 4.

Figure 4 shows that $p_{r o}^{*} \leq p_{r t c}^{*}(B) \leq p_{r c}^{*}(B)$ is holding. It can be interpreted that the capital constraint makes the retailer raise the retail price from $p_{r o}^{*}$ to $p_{r c}^{*}(B)$, while trade credit could decrease the retail price from $p_{r c}^{*}(B)$ to $p_{r t c}^{*}(B)$. Note that even financed by trade credit for free, the retailer with capital constraint is reluctant to drop the retail price $p_{r c}^{*}(B)$ to $p_{r o}^{*}$ since a smaller marginal profit is not beneficial to him. It is interesting that if the trade-credit interest rate in a single-channel supply chain is zero, the order quantity and retail price decided by the retailer with a capital constraint can be the same as that in the case of no capital constraint. However, in the dual-channel supply chain of this study, the trade credit with zero interest rate does not make the retailer's order quantity and the retail price reaches the level of no capital constraint. Furthermore, the results involved in Figures 3 and 4 demonstrate that trade credit may not be attractive enough to a capital-constrained retailer under certain conditions, which generate suggestions to answer the first question presented in the introduction section.

Next, we make a comparison among the profit of the manufacturer under the above three scenarios in Figure 5.

When the retailer's capital constraint hurts the manufacturer's profit (such as in the cases described in Lemma 2), Figure 5 exhibits that providing trade credit can greatly improve the manufacturer's profit to far exceed that without capital constraint when retailer's initial capital $B$ is extremely low. But for the manufacturer, benefits brought by tradecredit provision gradually shrinks to zero as $B$ increases up to $B_{1}$, so no trade-credit provision is not the better choice for the manufacturer when $B \geq B_{1}$. Figure 5 also shows when providing trade-credit service is beneficial for the manufacturer.

Last, according to the results presented in Proposition 3, the conditions about $z_{r}$ (the unit sales cost in the retail channel) and the conditions about $B$ (the initial capital of retailer) could form a closed area in a two-dimensional plane. With the parameter set $w=0.28, c=0.15, v=0.9, t_{d}=0.1, t_{r}=0.12$, $\theta=0.65, z_{d}=0.24$, we plot out the feasible region of each trade-credit strategy for the manufacturer in Figure 2.

Figure 2 is a two-dimensional plane that takes $z_{r}$ as the $X$-axis and $B$ as the $Y$-axis. The boundaries of each region, respectively, correspond to the thresholds of $B$ presented in Proposition 3. We can observe the feasible regions for the manufacturer to adopt each trade-credit strategy. In the leftside area, the manufacturer should provide trade credit with a positive interest rate; in the middle area, the manufacturer should offer trade credit for free; in the right-side area, there is no need to adopt trade credit. It exactly guides the manufacturer to strategically provide trade credit.

\section{Discussions and Conclusions}

6.1. Summary. It is important for the manufacturer to strategically provide trade credit to a capital-constrained retailer in a dual-channel supply chain. We carefully study pricing and trade-credit strategies for the manufacturer in this study. Through building a Stackelberg game model with a manufacturer-leader and a retailer-follower, we first reveal 


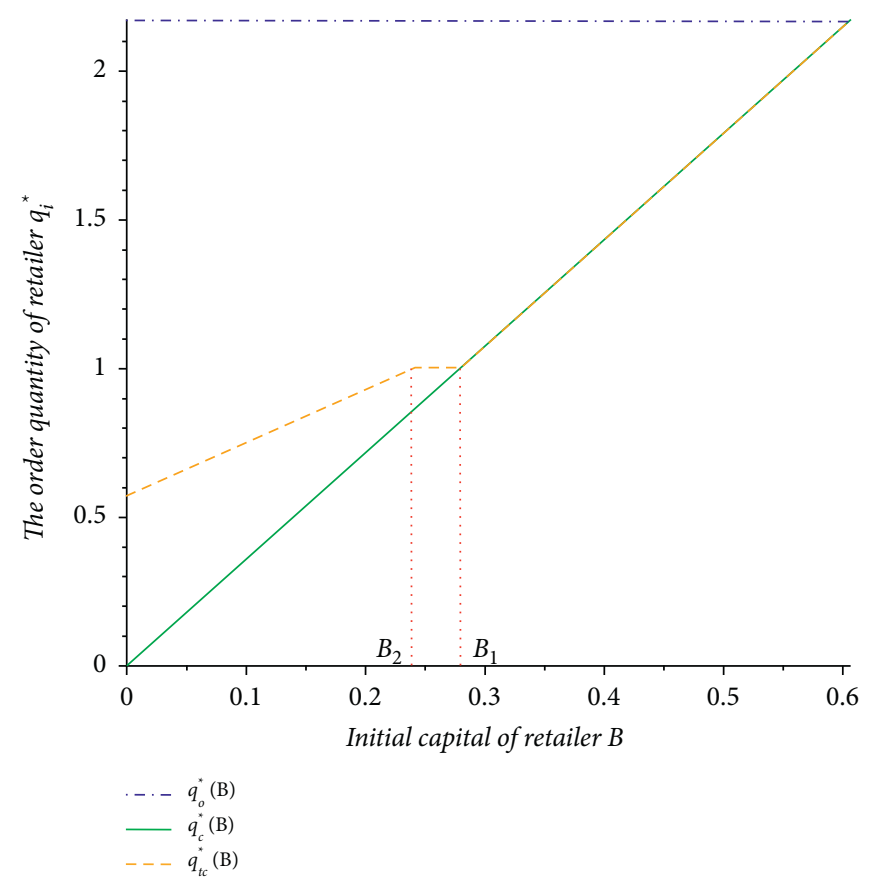

FIGURE 3: Retailer's optimal order quantity under three scenarios $(i=o, c, t c)$.

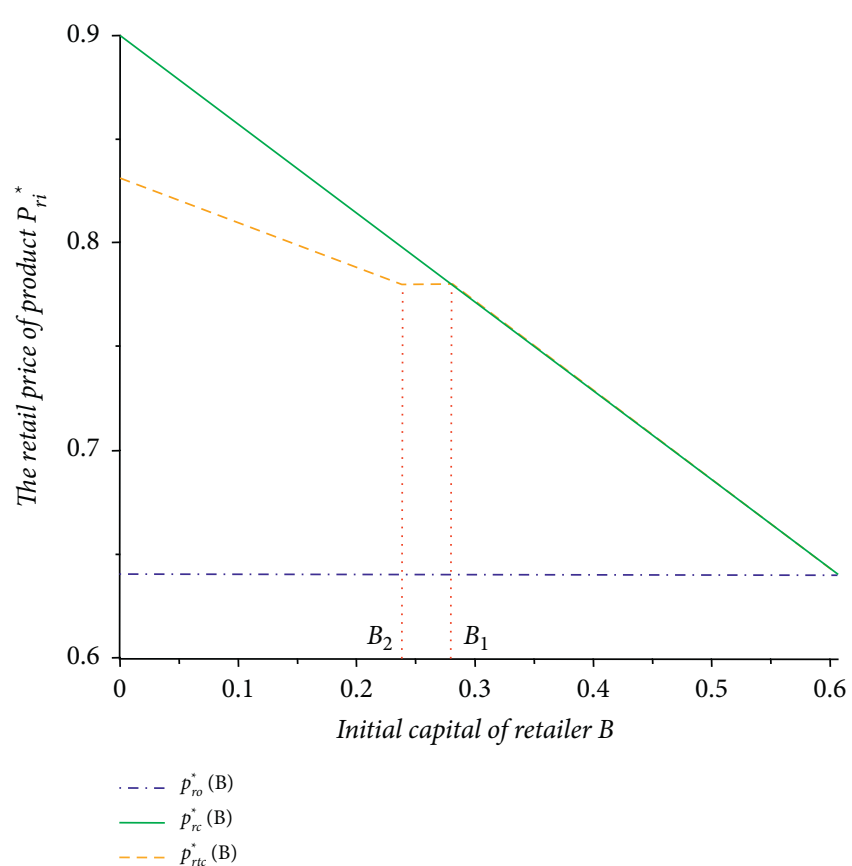

FIgURE 4: The equilibrium retail price under three scenarios $(i=o, c, t c)$.

the closed-form equilibrium prices for both supply chain members, and it can be found that the equilibrium prices are simultaneously affected by unit sale cost in both channels and consumers' acceptance level of the direct channel. Second, supplementary pricing strategy and competitive pricing strategy are presented in our results, and we conclude that the former one is the better choice for the manufacturer when the retailer suffers capital constraint.
Third, when the manufacturer's profit is hurt by the retailer's capital constraint, we verify that the manufacturer should strategically provide trade-credit service to the retailer rather than unconditionally provide it. We further present two trade-credit strategies (trade credit with a positive interest rate and trade credit with zero interest rate) and suggest the manufacturer choose the appropriate one according to the retailer's initial capital and unit sales cost in the retail channel. Lastly, to guide the manufacturer when and how to provide trade credit, we further conduct several numerical simulations to plot out the feasible region for each tradecredit strategy based on corresponding conditions.

6.2. Managerial Insights for Supply Chain Members. This study offers several managerial implications for both retailer and manufacturer. As far as the retailer is concerned, a capital constraint certainly reduces the order quantity, and it seems to must be financed by a bank or the manufacturer. However, the retailer knows that it certainly occurs a cost of financings, such as an interest rate for a loan or a delayed payment. So, in a dual-channel supply chain, the capital-constrained retailer may not choose the trade-credit service even if the manufacturer provides it, especially when the increment of profit cannot cover the cost caused by trade credit.

In terms of the manufacturer, our results help the manufacturer find the answers to the questions put forward in the introduction section. In a dual-channel supply chain, the manufacturer could make decisions on trade credit according to the following basis references. First, trade credit may not appeal to a capital-constrained retailer, although capital constraint decreases the retailer's profit. Second, trade credit not only increases the manufacturer's wholesale revenue and brings income by interest rate but also causes 


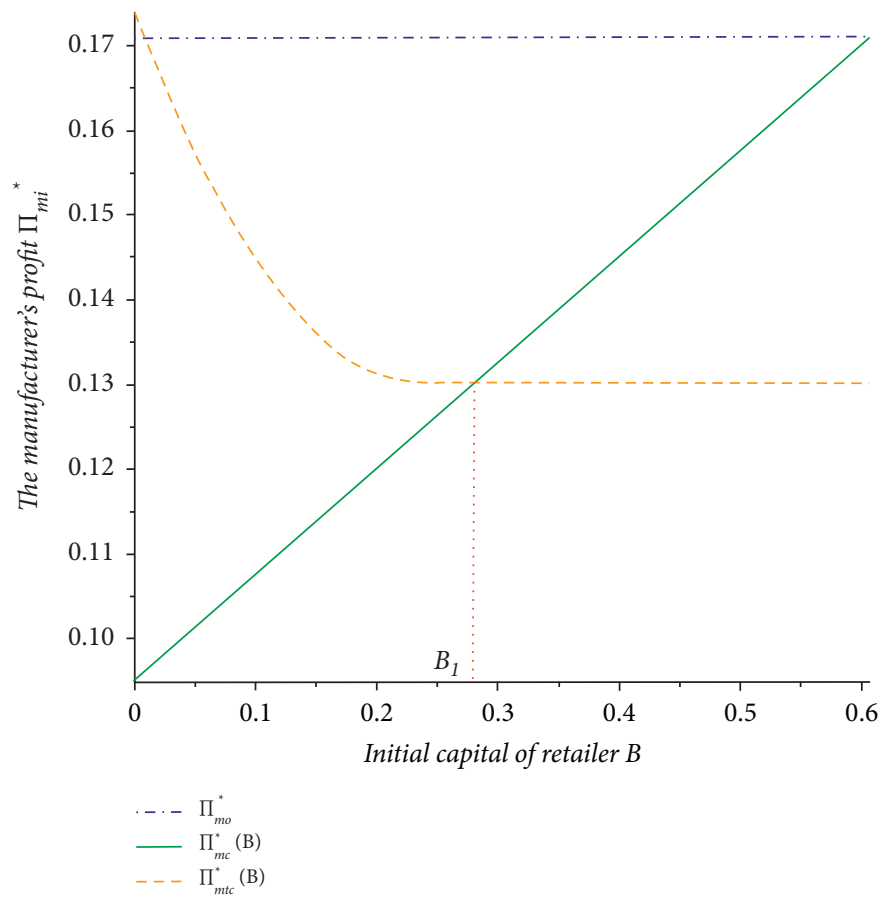

FIgURE 5: The manufacturer's profit under three scenarios $(i=o, c, t c)$.

profit loss since the competition between two channels is intensified. Understandably, it is not a wise choice to offer trade credit if the increment of the manufacturer's profit cannot cover the profit loss. Lastly, if the manufacturer determines to provide trade credit to a retailer, a supplementary pricing strategy is better than a competitive pricing strategy. Additionally, the manufacturer should strategically choose trade credit with a positive interest rate strategy or trade credit with a zero interest rate strategy based on the value of the retailer's initial capital and the value of unit sales cost in the retail channel.

To sum it up, the capital constraint on a retailer plays the role of a "double-edged sword" in a dual-channel supply chain. Therefore, the manufacturer should make good use of it. Our findings also warn manufacturers that it is necessary to pay attention to the unit sales cost in both retail and direct channels, and these factors have significant impacts on the manufacturer's pricing and trade-credit strategy. Manufacturers who aim to design trade-credit terms should carefully make a tradeoff between the benefit from trade-credit provision (including expanded wholesale revenue and income brought by interest rate) and the profit loss from an intensified competition.

6.3. Limitations and Future Research. There are some limitations to our model. Although we suppose there is one retailer in a dual-channel supply chain, considering multiple competitive retailers would be more meaningful. It can be conducted by a static game model to investigate the two competing retailers' decisions and a dynamic game model to explore the equilibrium strategies of the manufacturer and retailers. In our model, the consumers' acceptance level of the direct online channel is public information, but both members of the supply chain may not be able to obtain the exact value of it. So, it is necessary to absorb uncertainties of parameters in the future. Additionally, the terms we focus on include the interest rate and the sales price of the direct channel, accommodating more terms into the trade-credit contract may be an interesting extension for future research although there may be more difficulties in the calculation.

\section{Data Availability}

This research was conducted by a game theory model rather than an empirical study. So it does not contain empirical data.

\section{Conflicts of Interest}

The authors declare that they have no conflicts of interest.

\section{Acknowledgments}

This work was supported by the National Natural Science Foundation of China (no. 72001182), the National Social Science Foundation of China (no. 21BZZ058), the Ministry of Education of Humanities and Social Sciences (project no. 18YJA630071 and project no. 19YJC630159), the Young Scholars Development Fund of SWPU (no. 201899010068), and the Special Fund for Humanities and Social Sciences of Southwest Petroleum University (no. 2020RW037 and no. 2021RW060).

\section{References}

[1] M. A. Petersen and R. G. Rajan, "Trade credit: theories and evidence," Review of Financial Studies, vol. 10, no. 3, pp. 661-691, 1997.

[2] D. Piasecki, Consignment Inventory: What is It and When Does It Make Sense to Use It? White Paper, Inventory Operations Consulting LLC, Kenosha, WI, USA, 2004. 
[3] Z. Molamohamadi, M. Rezaeiahari, and N. Ismail, "Consignment inventory: review and critique of literature," Journal of Basic and Applied Scientific Research, vol. 3, no. 6, pp. 707-714, 2013.

[4] Z. Molamohamadi, N. Ismail, Z. Leman, and N. Zulkifli, "Reviewing the literature of inventory models under trade credit contact," Discrete Dynamics in Nature and Society, vol. 2014, Article ID 975425, 19 pages, 2014.

[5] G. G. Cai, X. Chen, and Z. Xiao, "The roles of bank and trade credits: theoretical analysis and empirical evidence," Production and Operations Management, vol. 23, no. 4, pp. 583-598, 2014.

[6] K.-Y. Chen, M. Kaya, and Ö. Özer, "Dual sales channel management with service competition," Manufacturing \& Service Operations Management, vol. 10, no. 4, pp. 654-675, 2008.

[7] H. Xu, Z. Z. Liu, and S. H. Zhang, "A strategic analysis of dualchannel supply chain design with price and delivery lead time considerations," International Journal of Production Economics, vol. 139, no. 2, pp. 654-663, 2012.

[8] Y. Xiong, W. Yan, K. Fernandes, Z.-K. Xiong, and N. Guo, "“Bricks vs. clicks": the impact of manufacturer encroachment with a dealer leasing and selling of durable goods," European Journal of Operational Research, vol. 217, no. 1, pp. 75-83, 2012.

[9] W. Yan, Y. Li, Y. Wu, and M. Palmer, "A rising E-channel tide lifts all boats? The impact of manufacturer multichannel encroachment on traditional selling and leasing," Discrete Dynamics in Nature and Society, vol. 2016, Article ID 2898021, 18 pages, 2016.

[10] Z. Jing, X. Hou, Y. Guo, and W. Jie, "Pricing policies for complementary products in a dual-channel supply chain," Applied Mathematical Modelling, vol. 49, pp. 437-451, 2017.

[11] L. Gao, L. Guo, and A. Orsdemir, "Dual-channel distribution: the case for cost information asymmetry," Production and Operations Management, vol. 30, no. 2, pp. 494-521, 2021.

[12] H. Hu, Q. Wu, S. Han, and Z. Zhang, "Coordination of dualchannel supply chain with perfect product considering sales effort," Advances in Production Engineering \& Management, vol. 15, no. 2, 2020.

[13] K. Matsui, "Optimal bargaining timing of a wholesale price for a manufacturer with a retailer in a dual-channel supply chain," European Journal of Operational Research, vol. 287, no. 1, pp. 225-236, 2020.

[14] S. Balasubramanian, "Mail versus mall: a strategic analysis of competition between direct marketers and conventional retailers," Marketing Science, vol. 17, no. 3, pp. 181-195, 1998.

[15] T.-P. Liang and J.-S. Huang, "An empirical study on consumer acceptance of products in electronic markets: a transaction cost model," Decision Support Systems, vol. 24, no. 1, pp. 29-43, 1998.

[16] J. J. Kacen, J. D. Hess, and W.-Y. Kevin Chiang, "Bricks or clicks? Consumer attitudes toward traditional stores and online stores," Global Economics and Management Review, vol. 18, no. 1, pp. 12-21, 2013.

[17] W.-y. K. Chiang, D. Chhajed, and J. D. Hess, "Direct marketing, indirect profits: a strategic analysis of dual-channel supply-chain design," Management Science, vol. 49, no. 1, pp. 1-20, 2003.

[18] P. Zhang, Y. He, and C. Shi, "Retailer's channel structure choice: online channel, offline channel, or dual channels?" International Journal of Production Economics, vol. 191, pp. 37-50, 2017.
[19] Z. Pei and R. Yan, "National advertising, dual-channel coordination and firm performance," Journal of Retailing and Consumer Services, vol. 20, no. 2, pp. 218-224, 2013.

[20] G. Hua, S. Wang, and T. C. E. Cheng, "Price and lead time decisions in dual-channel supply chains," European Journal of Operational Research, vol. 205, no. 1, pp. 113-126, 2010.

[21] T. M. Rofin and B. Mahanty, "Optimal dual-channel supply chain configuration for product categories with different customer preference of online channel," Electronic Commerce Research, vol. 18, no. 3, pp. 507-536, 2018.

[22] J. Guo, B. Cao, W. Xie, Y. Zhong, and Y.-W. Zhou, "Impacts of pre-sales service and delivery lead time on dual-channel supply chain design," Computers \& Industrial Engineering, vol. 147, Article ID 106579, 2020.

[23] C. W. Haley and R. C. Higgins, "Inventory policy and trade credit financing," Management Science, vol. 20, no. 4, pp. 464-471, 1973.

[24] S. K. Goyal, "Economic order quantity under conditions of permissible delay in payments," Journal of the Operational Research Society, vol. 36, no. 4, pp. 335-338, 1985.

[25] C.-T. Chang, J.-T. Teng, and S. K. Goyal, "Inventory lot-size models under trade credits: a review," Asia-Pacific Journal of Operational Research, vol. 25, no. 1, pp. 89-112, 2008.

[26] H. Soni, N. H. Shah, and C. K. Jaggi, "Inventory models and trade credit: a review," Control and Cybernetics, vol. 39, no. 3 , pp. 867-880, 2010.

[27] C. S. Tang, S. A. Yang, and J. Wu, "Sourcing from suppliers with financial constraints and performance risk," Manufacturing \& Service Operations Management, vol. 20, no. 1, pp. 70-84, 2018.

[28] C. Zhang, Y. Wang, Y. Wang, Y. Liu, and H. Wang, "Coordination contracts for a dual-channel supply chain under capital constraints," Journal of Industrial \& Management Optimization, vol. 17, no. 3, pp. 1485-1504, 2021.

[29] S. Xu, H. Tang, and Z. Lin, "Inventory and ordering decisions in dual-channel supply chains involving free riding and consumer switching behavior with supply chain financing," Complexity, vol. 2021, Article ID 55, 23 pages, 2021.

[30] H. Peura, S. A. Yang, and G. Lai, "Trade credit in competition: a horizontal benefit," Manufacturing \& Service Operations Management, vol. 19, no. 2, pp. 263-289, 2017.

[31] D. Ren, Y. Lan, C. Shang, J. Wang, and C. Xue, "Impacts of trade credit on pricing decisions of complementary products," Computers \& Industrial Engineering, vol. 146, Article ID 106580, 2020.

[32] X. Xu and J. R. Birge, "Joint-production-and-financing-decisions-modeling-and-analysis," 2004, http://ssrn.com/ abstract $=652562$.

[33] A. Daripa and J. Nilsen, "Ensuring sales: a theory of inter-firm credit," American Economic Journal: Microeconomics, vol. 3, no. 1, pp. 245-279, 2011.

[34] X. Chen and A. Wang, "Trade credit contract with limited liability in the supply chain with budget constraints," Annals of Operations Research, vol. 196, no. 1, pp. 153-165, 2012.

[35] S. A. Yang and J. R. Birge, "Trade credit, risk sharing, and inventory financing portfolios," Management Science, vol. 64, no. 8, pp. 3667-3689, 2018.

[36] N. Yan and X. He, "Optimal trade credit with deferred payment and multiple decision attributes in supply chain finance," Computers \& Industrial Engineering, vol. 147, Article ID 106627, 2020.

[37] J. Zhan, X. Chen, and J. Huang, "Trade credit financing for two competitive retailers in a capital-constrained supply 
Chain," Asia-Pacific Journal of Operational Research (APJOR), vol. 38, no. 2, pp. 1-32, 2021.

[38] Q. Lin and Y. Xiao, "Retailer credit guarantee in a supply chain with capital constraint under push \& pull contract," Computers \& Industrial Engineering, vol. 125, pp. 245-257, 2018.

[39] P. Kouvelis and W. Zhao, "Financing the newsvendor: supplier vs. bank, and the structure of optimal trade credit contracts," Operations Research, vol. 60, no. 3, pp. 566-580, 2012.

[40] B. Jing, X. Chen, and G. G. Cai, "Equilibrium financing in a distribution channel with capital constraint," Production and Operations Management, vol. 21, no. 6, pp. 1090-1101, 2012.

[41] D. Gupta, Technical Note: Financing the Newsvendor, Working Paper, University of Minnesota, Twin Cities, Minneapolis, MN, USA, 2008.

[42] X. Chen, "A model of trade credit in a capital-constrained distribution channel," International Journal of Production Economics, vol. 159, pp. 347-357, 2015.

[43] N. Yan, Y. Liu, X. Xu, and X. He, "Strategic dual-channel pricing games with e-retailer finance," European Journal of Operational Research, vol. 283, no. 1, pp. 138-151, 2020.

[44] N. Yan, Y. Zhang, X. Xu, and Y. Gao, "Online finance with dual channels and bidirectional free-riding effect," International Journal of Production Economics, vol. 231, Article ID 107834, 2021.

[45] G. Li, H. Wu, and S. Xiao, "Financing strategies for a capitalconstrained manufacturer in a dual-channel supply chain," International Transactions in Operational Research, vol. 27, no. 5, pp. 2317-2339, 2020.

[46] X. Zhen, D. Shi, Y. Li, and C. Zhang, "Manufacturer's financing strategy in a dual-channel supply chain: third-party platform, bank, and retailer credit financing," Transportation Research Part E: Logistics and Transportation Review, vol. 133, Article ID 101820, 2020.

[47] R. Yan, S. Ghose, and A. Bhatnagar, "Cooperative advertising in a dual channel supply chain," International Journal of Electronic Marketing and Retailing, vol. 1, no. 2, pp. 99-114, 2006. 